\title{
More research is needed before we regard POP-Q stage 1 prolapse as normal
}

\author{
Marian Wiegersma • Chantal M. C. R. Panman • \\ Yvonne Lisman-Van Leeuwen • Janny H. Dekker
}

Received: 27 February 2014 / Accepted: 7 March 2014 / Published online: 4 July 2014

(C) The International Urogynecological Association 2014

Dear Editor,

With great interest we read the article by Dietz and Mann entitled "What is clinically relevant prolapse? An attempt at defining cutoffs for the clinical assessment of pelvic organ descent" [1]. In this article, the authors try to find an optimal cutoff value for predicting prolapse symptoms.

Their results show a strong relation between prolapse symptoms and the POP-Q measurement points $\mathrm{Ba}, \mathrm{C}$, and $\mathrm{Bp}$, with the optimal cutoff value for $\mathrm{Ba}$ and $\mathrm{Bp}$ being -0.5 . In their conclusion, the authors therefore argue that mild (stage 1) prolapse of the anterior and posterior vaginal wall should be regarded as part of the normal range. Because the study was conducted in a tertiary urogynecological unit, this conclusion may not be generalizable to the general population. Furthermore, prolapse symptoms were defined as the sensation of a lump or bulge and/or a dragging sensation in the vagina, while other possibly prolapse-related symptoms, like pain in the lower back or abdomen and urinary or bowel symptoms, are not accounted for.

Regarding mild prolapse of the anterior and posterior vaginal wall as part of the normal range indicates that there is no treatment indication. However, there is some evidence that women with mild pelvic organ prolapse benefit from pelvic floor muscle therapy (PFMT) [2-4]. Current evidence for the effectiveness of PFMT in women with mild prolapse comes from small studies, two of which are pilot studies $[2,3]$ and the other is of moderate methodological quality [4].

A larger trial investigating the effect of PFMT compared with watchful waiting in a primary care population of women aged $\geq 55$ years with symptomatic mild POP is currently ongoing [5].
We agree with the authors that mild pelvic organ prolapse is probably not an indication for surgical correction, but it may be an indication for conservative treatment like pelvic floor muscle training. More research, preferably in a primary care population, is needed before we decide to regard stage 1 prolapse of the anterior and posterior vaginal wall as normal.

Conflict of interest The authors declare that they have no conflicts of interest.

\section{References}

1. Dietz HP, Mann KP (2014) What is clinically relevant prolapse? An attempt at defining cutoffs for the clinical assessment of pelvic organ descent. Int Urogynecol J 25:451-455. doi:10.1007/s00192-013-2307-4

2. Hagen S, Stark D, Glazener C, Sinclair L, Ramsay I (2009) A randomized controlled trial of pelvic floor muscle training for stages I and II pelvic organ prolapse. Int Urogynecol J Pelvic Floor Dysfunct 20(1): $45-51$

3. Stupp L, Resende AP, Oliveira E, Castro RA, Girao MJ, Sartori MG (2011) Pelvic floor muscle training for treatment of pelvic organ prolapse: an assessor-blinded randomized controlled trial. Int Urogynecol J 22(10):1233-1239

4. Ghroubi S, Kharrat O, Chaari M, Ben Ayed B, Guermazi M, Elleuch MH (2008) Effect of conservative treatment in the management of low-degree urogenital prolapse. Ann Readapt Med Phys 51(2):96-102

5. Wiegersma M, Panman CM, Kollen BJ, Vermeulen KM, Schram AJ, Messelink EJ, Berger MY, Lisman-Van Leeuwen Y, Dekker JH (2014) Pelvic floor muscle training versus watchful waiting or pessary treatment for pelvic organ prolapse (POPPS): design and participant baseline characteristics of two parallel pragmatic randomized controlled trials in primary care. Maturitas 77(2):168-173

M. Wiegersma • C. M. C. R. Panman • Y. Lisman-Van Leeuwen ·

J. H. Dekker $(\triangle)$

Department of General Practice, FA21, University of Groningen,

University Medical Center Groningen, P.O. Box 196,

9700 AD Groningen, The Netherlands

e-mail: j.h.dekker@umcg.nl 